\title{
Laboratory Characterization and Influence of Mineralogy and Grading on the Performance of Treated and Untreated Granular Materials Used as Surface Pavements in Unpaved Road
}

\author{
L. Beaulieu, P. Pierre, and J.-P. Bilodeau \\ Département de Génie Civil, Université Laval 1065, Avenue de la Médecine, Pavillon Adrien Pouliot, QC, Canada G1V $0 A 6$ \\ Correspondence should be addressed to P. Pierre, pascale.pierre@gci.ulaval.ca \\ Received 16 December 2009; Revised 1 April 2010; Accepted 6 June 2010 \\ Academic Editor: Cumaraswamy Vipulanandan
}

Copyright (C) 2010 L. Beaulieu et al. This is an open access article distributed under the Creative Commons Attribution License, which permits unrestricted use, distribution, and reproduction in any medium, provided the original work is properly cited.

\begin{abstract}
This paper presents the results of a laboratory study on the influence of grading and granular mineralogy sources (granitic gneiss, basalt and limestone) on the performance of treated and untreated granular materials used as surface pavements in unpaved roads. Results of bearing capacity, resilient modulus and compressive strength tests are discussed. Natural brine, calcium chloride, cement and a polymer emulsion treated samples were tested and compared to untreated samples. The combinations of product, mineralogy and grading showing great performance are finally pointed out.
\end{abstract}

\section{Introduction}

The performance of unpaved roads is directly affected by environmental stresses such as wind, rain, water, frost, as well as mechanical stresses from vehicle tires, heavy axle loads, and traffic volumes. The characteristics and mineralogy of granular materials used as surfacing material also affect road performance. A combination of these factors may cause surface distress such as rutting, corrugation, potholes, and erosion among others, which can affect users comfort and safety. Therefore, road maintenance must be carried out regularly to maintain the pavement serviceability to an acceptable level. Road maintenance is expensive and thus costs a lot of money to unpaved road network managers.

Because of their rapid deterioration rate, most unbound granular materials used as surfacing materials for unpaved roads are treated in order to provide a better ride quality for users and to extend the service life of the material. There is an economical advantage to unpaved road surface treatments, which is costly but usually reduces maintenance costs (Sanders et al. [1]). Many types of products are used to increase the general performance of unpaved roads. Dust suppressant agents such as alkali-chloride solutions, lime, and resins are used to reduce excessive dust problems causing safety and respiratory hazards. On the other hand, stabilization agents like cement, bituminous, and polymer emulsions are used to reduce road deterioration problems related to traffic such as rutting.

The effect of several products has been widely studied and reported by the scientific community. While it is recognized that most dust suppressant agents do not significantly improve the bearing capacity (Doré et al. [2], Pelletier [3], and Pierre et al. [4, 5]), stabilization agents generally improve both bearing capacity and dust-lifting resistance due to the strong cohesion forces brought to the unbound granular material skeleton. A recent study by Pelletier [3] demonstrated with direct shear tests that shear resistance tends to increase with compaction for water content from $3 \%$ to $6 \%$ for calcium chloride, natural brine, cement, and polymer emulsion.

In addition, Pierre et al. [4] showed that performance measured with bearing capacity, compressive strength, and resilient modulus tests increases with natural brine, polymer emulsion, and cement contents for equivalent compaction water content while it decreases for the calcium chloride. The results obtained indicate that polymer emulsion or natural brine content samples presented similar performances to low cement content samples. The study from Doré et al. [2] previously demonstrated the mechanical advantages of using polymer or natural brine for mechanical stabilization while 
the studies from Bergeron [6], Pouliot [7], and Santoni et al. [8] showed the mechanical advantages of cement and polymer emulsion for unpaved roads stabilization.

The objectives of this study were twofold: evaluate the influence of granular mineralogy (granitic gneiss, basalt, and limestone) and grading on the performance of treated and untreated granular materials and compare the performance of several dust suppressants and stabilization agents. Hence, this paper presents the results of three laboratory tests (bearing capacity, resilient modulus, and compressive strength) made on nine mineralogy and grading combinations. Each mineralogy and grading combination was treated with calcium chloride, natural brine, polymer emulsion, and cement at different concentration rates. Untreated specimens were also tested and used as a control to perform comparative analysis.

\section{Test Specimens}

As part of the CARRLo project (Pierre [9]), this study is an extend of the laboratory investigation described in Pierre et al. [5]. The different grain-size distributions of the aggregate sources are presented in Figures 1, 2, and 3 while the main geotechnical properties of the three types of aggregate are shown in Table 1. For each aggregate source, three different gradations were tested. Experience shows that the three gradings tested are good approximations of the possible gradings that usually take place on unpaved roads (Beaulieu et al. [10]).

For each gradation of each source, the optimal compaction water content was pointed out and remains constant while the treating product concentration rate varies. The tests were also performed on untreated granular materials to get the relative effect of the products on the performance of the granular materials (treated material test results divided by untreated material test results). The granular materials were treated with two different types of additives which are dust suppressants and stabilization agents.

The dust suppressants are a natural brine $(60 \%$ of $\mathrm{CaCl}_{2}, 37 \%$ of $\mathrm{NaCl}, 2 \%$ of $\mathrm{MgCl}_{2}$, and $1 \%$ of $\mathrm{KCl}$ ) and calcium chloride $\left(94 \%\right.$ of $\mathrm{CaCl}_{2}, 3.7 \%$ of $\mathrm{NaCl}, 0.04 \%$ of $\mathrm{MgCl}_{2}$, and other impurities). The two dust suppressants are hygroscopic products. The stabilization agents are aqueous acrylic vinyl acetate polymer emulsion and cement (type $\mathrm{GU})$. Table 2 presents the curing period for each test and the concentrations tested per product, which are mostly based on the supplier specifications and experience (Pelletier [3], Pierre et al. 2007, $2008[4,5])$.

It should be pointed out that each test was performed three times for a given product and concentration in order to obtain more representative results by using average values.

For the resilient modulus and bearing capacity tests, samples were compacted in four layers with a vibrating hammer (Figure 5) inside ABS plastic moulds with an internal diameter of $152.4 \mathrm{~mm}$, a wall thickness of $7.7 \mathrm{~mm}$ and a height of $152.4 \mathrm{~mm}$ (Figure 4). Each layer had the same thickness $(25 \mathrm{~mm} \pm 1 \mathrm{~mm})$ and was compacted during one minute. After compaction, the surface of each

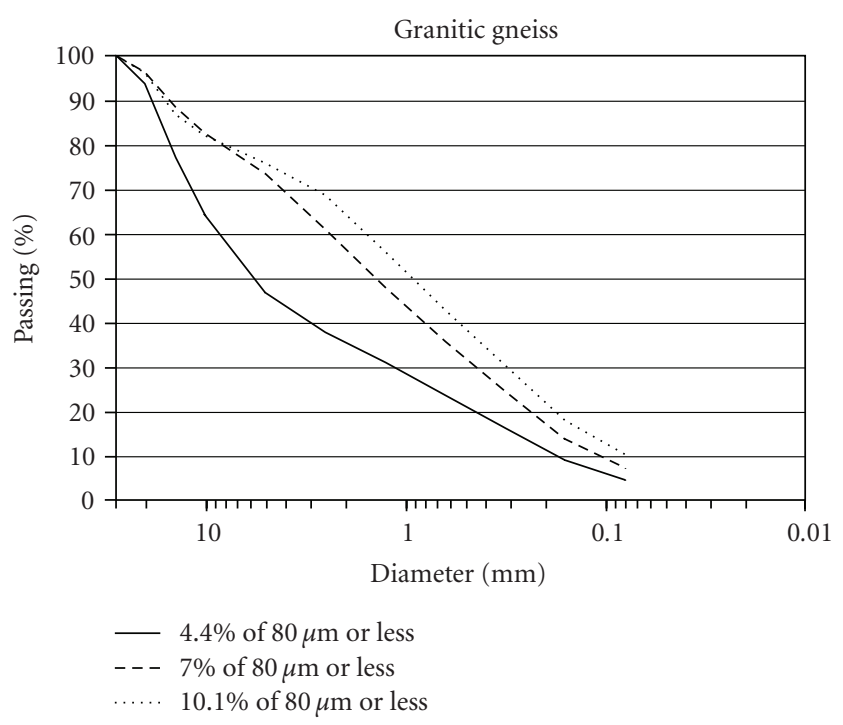

FIGURE 1: The three different gradings for granitic gneiss.

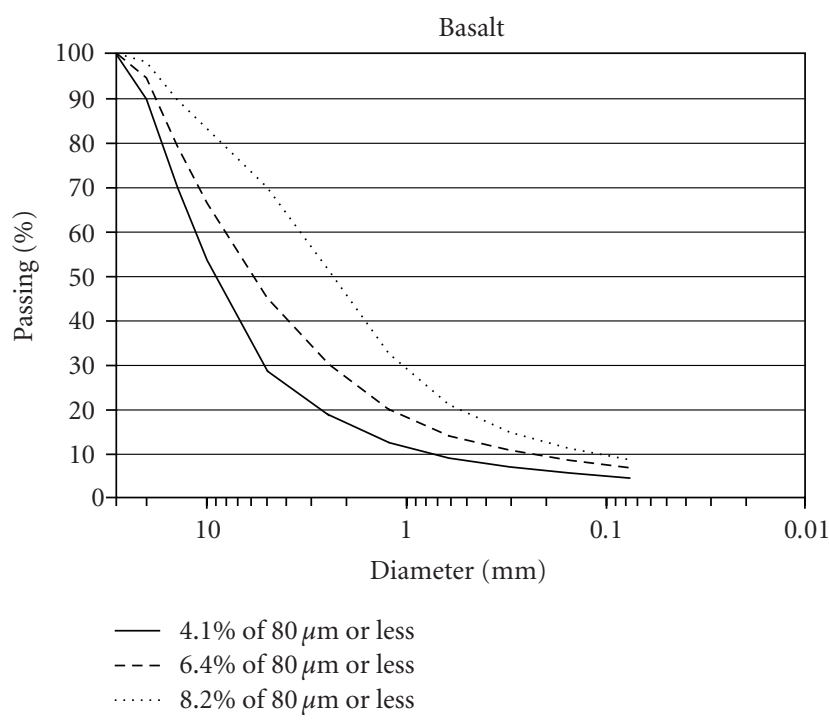

FIGURE 2: The three different gradings for basalt.

layer was scarified to make sure that the sample remains homogeneous.

For the compressive strength, the samples were also compacted in 4 layers of the same thickness $(50 \mathrm{~mm} \pm 1 \mathrm{~mm}$ ) put in a mould with an internal diameter of $101.4 \mathrm{~mm}$ and a height of $202.8 \mathrm{~mm}$ (Figure 4). The compaction procedure was the same as the one for the resilient modulus and bearing capacity tests (Figure 5). The samples were all compacted at their optimum water content which includes the water content of the product (Table 1).

For each mineralogy and grading combination, the optimum water content was determined with modify Proctor test (Beaulieu et al. [10]). 
TABLE 1: Main geotechnical properties of the three types of aggregate.

\begin{tabular}{|c|c|c|c|c|c|c|}
\hline & Grading (\% of $80 \mu \mathrm{m}$ less) & Optimum water content (\%) & Methylene blue value $\left(\mathrm{cm}^{3} / \mathrm{g}\right)$ & $\rho_{d \max }\left(\mathrm{kg} / \mathrm{m}^{3}\right)$ & $\rho_{s}\left(\mathrm{~kg} / \mathrm{m}^{3}\right)$ & $C_{u}$ \\
\hline \multirow{3}{*}{ Granitic gneiss } & 4.4 & 4.5 & \multirow{3}{*}{0.046} & 2212 & \multirow{3}{*}{2640} & 40 \\
\hline & 7 & 6.8 & & 2045 & & 20 \\
\hline & 10.1 & 7.4 & & 2020 & & 19 \\
\hline \multirow{3}{*}{ Basalt } & 4.1 & 4.5 & \multirow{3}{*}{0.383} & 2180 & \multirow{3}{*}{2780} & 13 \\
\hline & 6.4 & 5.75 & & 2288 & & 29 \\
\hline & 8.2 & 6.2 & & 2327 & & 23 \\
\hline \multirow{3}{*}{ Limestone } & 3.8 & 4.2 & \multirow{3}{*}{0.600} & 2192 & \multirow{3}{*}{2610} & 10 \\
\hline & 6.6 & 5.6 & & 2220 & & 25 \\
\hline & 8.8 & 6 & & 2315 & & 45 \\
\hline
\end{tabular}

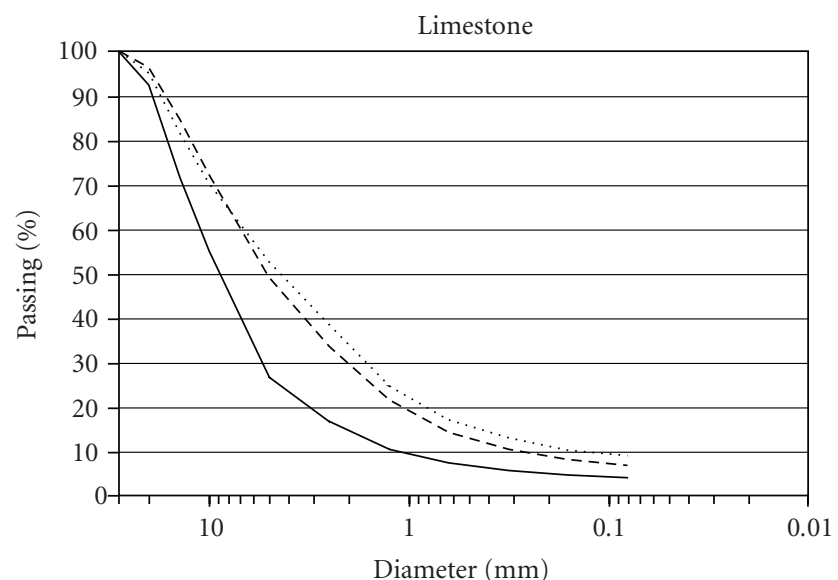

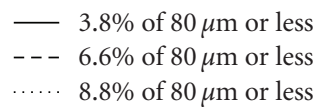

FIgURE 3: The three different gradings for limestone.

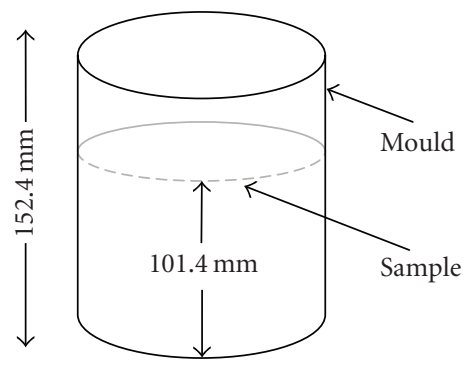

(a)

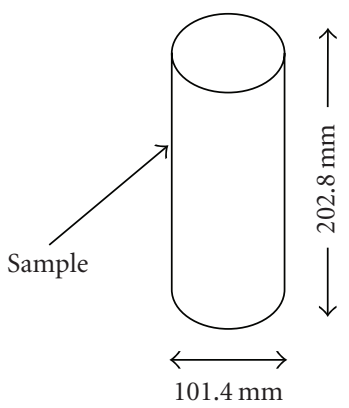

(b)
FIGURE 4: Scheme of the compacted samples for resilient modulus (a) and bearing capacity (a) tests and for compressive strength test (b).

A curing time of 7 days at $20^{\circ} \mathrm{C}$ was applied for the resilient modulus and bearing capacity tests samples and a curing time of 3 days was applied for the compressive strength test samples.

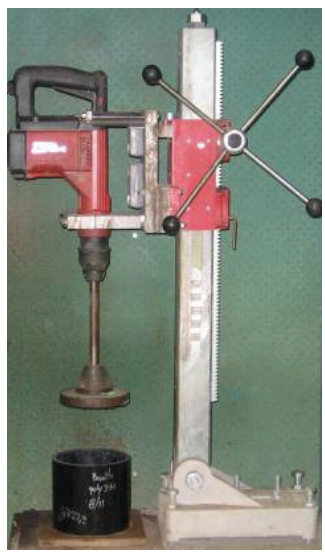

(a)

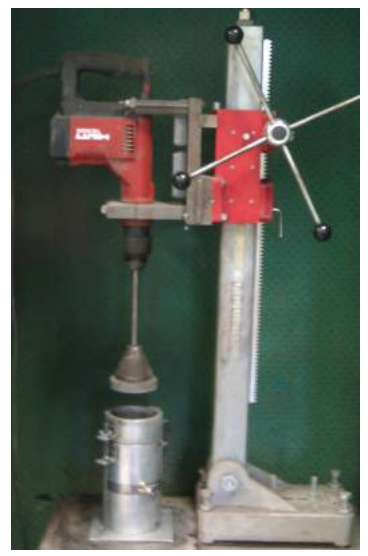

(b)
FIGURE 5: Samples compaction for resilient modulus (a) and bearing capacity (a) tests and for compressive strength test (b).

\section{Testing Program}

The mechanical performance of treated base granular materials is measured with $\mathrm{CBR}$, resilient modulus and compressive strength tests slightly modified from the original standards ASTM D1883 (ASTM 2007), AASHTO T-307 (AASHTO 2000), and ASTM D5102 (ASTM 2004). Figure 6 shows pictures of the three tests. Because several specimens needed to be prepared the same day, ABS moulds were used rather than ASTM standard steel moulds for both CBR and resilient modulus tests. On the other hand, the original steel mould was used to make the samples for the compressive strength test.

The resilient behaviour was measured on the bottom end of the sample, with the top end resting on an appropriate support (Figure 6(a)). Since the samples are inside the ABS moulds, the resilient behaviour can be compared to an oedometric resilient behaviour. The samples were submitted to 300 cycles with a vertical stress of $280 \mathrm{kPa}$ which is applied in a cyclic haversine manner. The axial cyclic stress has a load duration of 0.1 second and a total cycle duration of 1 second (which means a sleep duration of 0.9 second). To ensure a uniform contact with the samples, $10 \%$ of the total vertical stress is static while $90 \%$ is cyclic. This vertical 


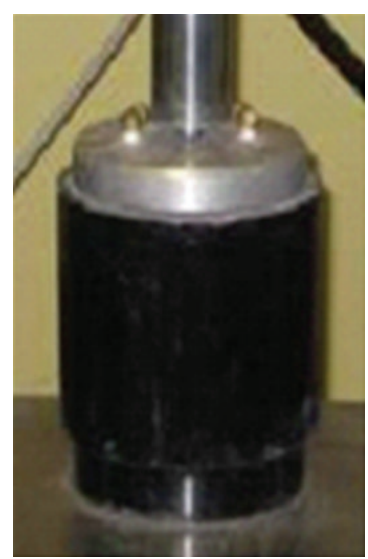

(a)

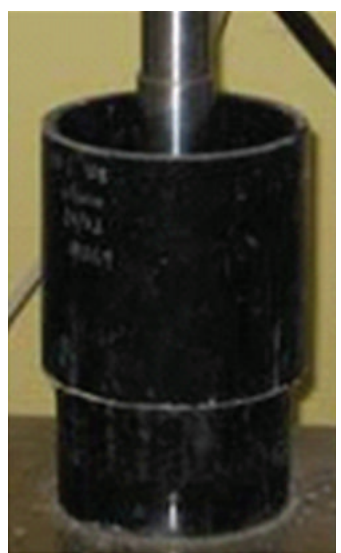

(b)

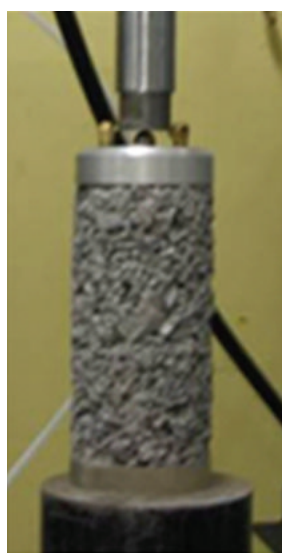

(c)

Figure 6: Scheme of the three performed tests (resilient modulus (a), bearing capacity (b), and compressive strength (c)).

stress level corresponds to a step level of $40 \mathrm{kN}$ made by an axle load. For each grading and additive, the mean of the resilient modulus between 295 and 300 cycles is recorded as the resilient behaviour performance parameter since most of the resilient deformation is found to be mostly stabilized after 150 to 200 cycles as stated by Pierre et al. [5].

The bearing capacity tests were conducted on the sample top end at a penetration rate of $2 \mathrm{~mm} / \mathrm{min}$ to reach a maximum penetration of $10 \mathrm{~mm}$ (Figure 6(b)). The strength recorded at a corrected $5 \mathrm{~mm}$ penetration is used as the reference force since statistical analysis showed that this value presents the highest correlation strength with the product concentration (Pierre et al. [5]).

The compressive strength tests were conducted on the top end of the sample at load rate of $0.8 \mathrm{~mm} / \mathrm{min}$ (Figure 6(c)). Compared to the two other tests, there is no restriction on the vertical area of the sample. The compressive strength of a sample is the value of uniaxial compressive stress reached when the material fails. So, the strength recorded is the maximum load supported by the sample without failure.

\section{Tests Results}

Since one of the principal objectives of this paper is to determine the efficiency of various products on the performance of granular materials used as surface pavements in unpaved road, the results are presented in Tables 3, 4, and 5 as relative results (Rel.). The relative result corresponds to the test result obtained for the treated granular material divided by the test result obtains for the untreated granular material. The absolute test values (Abs.) obtained for the untreated granular materials are also provided. For example, consider the combination of granitic gneiss with a $4.4 \%$ of $80 \mu \mathrm{m}$ grain size and less grading and a treatment with brine at a concentration of $1.2 \mathrm{~L} / \mathrm{m}^{2}$ (Table 3 ), the absolute result is $138 \mathrm{kN}(0,9 * 153 \mathrm{kN})$.

Performance gain or loss caused by various products can be pointed out with the presentation of relative results. The results in Tables 3, 4, and 5 show the important effect
TABLE 2: Products concentration and curing time for each test.

\begin{tabular}{lcc}
\hline Product & $M_{R} \quad$ CBR & $\begin{array}{c}\text { Compressive } \\
\text { strength }\end{array}$ \\
\hline Brine $\left(\mathrm{L} / \mathrm{m}^{2}\right)$ & 3 concentrations tested: $1.2 / 1.5 / 1.8$ \\
$\mathrm{CaCl}_{2}\left(\mathrm{~L} / \mathrm{m}^{2}\right)$ & 3 concentrations tested: $1.3 / 1.8 / 2.3$ \\
$\begin{array}{l}\text { Polymer }\left(\mathrm{L} / \mathrm{m}^{2}\right) \\
\text { Cement }(\%)\end{array}$ & 3 concentrations tested: $1.4 / 2.4 / 3.4$ \\
\hline $\begin{array}{l}\text { Curing time for each } \\
\text { sample treated or } \\
\text { untreated (days) }\end{array}$ & 7 & 3 \\
\hline
\end{tabular}

TABLE 3: Relative results for granitic gneiss for the 3 different gradings.

\begin{tabular}{lcccc}
\hline & \multicolumn{4}{c}{ Grading: 4.4\%/7\%/10.1\% (\% of $80 \mu \mathrm{m}$ or less $)$} \\
\hline Product & $\begin{array}{c}\text { Dosage } \\
\left(\mathrm{L} / \mathrm{m}^{2}, \%\right)\end{array}$ & $M_{R}$ & $\mathrm{CBR}$ & $\begin{array}{c}\text { Compressive } \\
\text { strength }\end{array}$ \\
\hline Brine & 1.2 & $0.9 / 1.1 / 1.3$ & $1.2 / 1.8 / 1.2$ & $1.4 / 1.1 / 1.1$ \\
Brine & 1.5 & $0.9 / 1.0 / 1.3$ & $1.1 / 1.7 / 1.1$ & $1.4 / 1.1 / 0.9$ \\
Brine & 1.8 & $0.9 / 1.0 / 1.3$ & $1.0 / 1.7 / 1.2$ & $1.3 / 1.3 / 0.9$ \\
$\mathrm{CaCl}_{2}$ & 1.3 & $0.9 / 0.9 / 1.2$ & $1.1 / 1.5 / 1.1$ & $1.3 / 1.0 / 0.8$ \\
$\mathrm{CaCl}_{2}$ & 1.8 & $0.8 / 0.9 / 1.4$ & $1.0 / 1.3 / 1.1$ & $1.1 / 1.1 / 0.9$ \\
$\mathrm{CaCl}_{2}$ & 2.3 & $0.8 / 1.0 / 1.3$ & $1.2 / 1.4 / 1.3$ & $1.0 / 0.8 / 0.9$ \\
Polymer & 1.4 & $1.1 / 1.1 / 1.3$ & $1.4 / 1.9 / 1.1$ & $2.2 / 1.1 / 1.5$ \\
Polymer & 2.4 & $1.1 / 1.1 / 1.3$ & $1.3 / 1.9 / 1.0$ & $3.3 / 1.1 / 1.2$ \\
Polymer & 3.4 & $1.1 / 0.9 / 1.3$ & $1.6 / 2.1 / 1.2$ & $4.4 / 2.7 / 1.5$ \\
Cement & 1.5 & $0.9 / 1.1 / 1.4$ & $3.7 / 1.9 / 2.5$ & $3.8 / 3.8 / 3.2$ \\
Cement & 3.5 & $1.1 / 1.1 / 1.9$ & $4.8 / 2.5 / 3.2$ & $6.0 / 9.8 / 6.4$ \\
Cement & 4.5 & $1.0 / 1.2 / 1.8$ & $6.3 / 2.9 / 3.3$ & $10.0 / 11.3 / 14.4$ \\
Cement & 6.0 & $1.1 / 1.3 / 1.7$ & $5.3 / 6.9 / 5.1$ & $10.8 / 14.3 / 19.8$ \\
Ref. & Rel. & $1.0 / 1.0 / 1.0$ & $1.0 / 1.0 / 1.0$ & $1.0 / 1.0 / 1.0$ \\
Ref. & Abs. ${ }^{*}$ & $153 / 137 / 100$ & $21 / 17 / 19$ & $2.8 / 2.5 / 2.4$ \\
\hline
\end{tabular}

${ }^{*} \mathrm{MPa}$ for $M_{R}$ tests, $\mathrm{kN}$ for $\mathrm{CBR}$ and compressive strength tests. 
TABLE 4: Relative results for basalt for the 3 different gradings.

\begin{tabular}{lcccc}
\hline \multicolumn{5}{c}{ Grading: $4.1 \% / 6.4 \% / 8.2 \%(\%$ of $80 \mu \mathrm{m}$ or less $)$} \\
\hline Product & $\begin{array}{c}\text { Dosage } \\
\left(\mathrm{L} / \mathrm{m}^{2}, \%\right)\end{array}$ & $M_{R}$ & $\mathrm{CBR}$ & $\begin{array}{c}\text { Compressive } \\
\text { strength }\end{array}$ \\
\hline Brine & 1.2 & $0.9 / 0.8 / 1.0$ & $0.6 / 0.6 / 0.9$ & $0.8 / 1.0 / 0.8$ \\
Brine & 1.5 & $0.8 / 0.9 / 1.1$ & $0.5 / 0.5 / 0.7$ & $0.6 / 1.0 / 0.7$ \\
Brine & 1.8 & $0.8 / 0.7 / 1.1$ & $0.7 / 0.6 / 0.7$ & $0.5 / 0.7 / 0.6$ \\
$\mathrm{CaCl}_{2}$ & 1.3 & $0.7 / 0.8 / 1.0$ & $0.6 / 0.7 / 0.7$ & $0.7 / 0.8 / 1.0$ \\
$\mathrm{CaCl}_{2}$ & 1.8 & $0.8 / 0.8 / 0.9$ & $0.5 / 0.6 / 0.7$ & $0.8 / 0.7 / 0.6$ \\
$\mathrm{CaCl}_{2}$ & 2.3 & $0.8 / 0.7 / 0.8$ & $0.6 / 0.7 / 0.7$ & $0.4 / 0.5 / 0.5$ \\
Polymer & 1.4 & $0.8 / 0.9 / 1.0$ & $1.4 / 1.1 / 0.9$ & $1.0 / 2.1 / 1.2$ \\
Polymer & 2.4 & $1.1 / 0.9 / 1.1$ & $1.3 / 1.1 / 0.9$ & $1.2 / 2.4 / 1.1$ \\
Polymer & 3.4 & $0.8 / 0.9 / 1.0$ & $1.4 / 1.1 / 0.8$ & $1.7 / 2.5 / 2.5$ \\
Cement & 1.5 & $1.0 / 0.9 / 1.4$ & $1.5 / 1.4 / 1.0$ & $2.0 / 2.6 / 3.8$ \\
Cement & 3.5 & $1.0 / 1.0 / 1.7$ & $2.5 / 2.7 / 1.6$ & $4.1 / 5.9 / 8.6$ \\
Cement & 4.5 & $1.0 / 1.0 / 1.8$ & $2.4 / 3.1 / 2.3$ & $6.0 / 8.7 / 11.3$ \\
Cement & 6.0 & $1.0 / 0.9 / 1.7$ & $3.3 / 4.1 / 2.3$ & $5.8 / 9.6 / 18.2$ \\
Ref. & Rel. & $1.0 / 1.0 / 1.0$ & $1.0 / 1.0 / 1.0$ & $1.0 / 1.0 / 1.0$ \\
Ref. & Abs. & $163 / 170 / 130$ & $17 / 22 / 24$ & $3.6 / 2.6 / 3.1$ \\
\hline
\end{tabular}

${ }^{*} \mathrm{MPa}$ for $M_{R}$ tests, $\mathrm{kN}$ for $\mathrm{CBR}$ and compressive strength tests.

TABLE 5: Relative results for limestone for the 3 different gradings.

\begin{tabular}{lcccc}
\hline \multicolumn{5}{c}{ Grading: 3.8\%/6.6\%/8.8\% (\% of $80 \mu \mathrm{m}$ or less) } \\
\hline Product & $\begin{array}{c}\text { Dosage } \\
\left(\mathrm{L} / \mathrm{m}^{2}, \%\right)\end{array}$ & $M_{R}$ & CBR & $\begin{array}{c}\text { Compressive } \\
\text { strength }\end{array}$ \\
\hline Brine & 1.2 & $0.9 / 1.1 / 0.9$ & $0.8 / 0.5 / 0.7$ & $0.4 / 1.1 / 1.0$ \\
Brine & 1.5 & $0.9 / 0.9 / 1.0$ & $0.9 / 0.5 / 0.7$ & $0.4 / 1.0 / 0.9$ \\
Brine & 1.8 & $0.8 / 0.9 / 0.9$ & $0.6 / 0.4 / 0.6$ & $0.3 / 1.0 / 0.8$ \\
$\mathrm{CaCl}_{2}$ & 1.3 & $0.8 / 0.8 / 1.0$ & $0.5 / 0.5 / 0.7$ & $0.6 / 0.9 / 1.0$ \\
$\mathrm{CaCl}_{2}$ & 1.8 & $0.8 / 0.8 / 0.9$ & $0.5 / 0.7 / 0.8$ & $0.3 / 0.8 / 1.1$ \\
$\mathrm{CaCl}_{2}$ & 2.3 & $0.8 / 0.8 / 0.9$ & $0.5 / 0.6 / 0.6$ & $0.3 / 0.7 / 1.1$ \\
Polymer & 1.4 & $1.1 / 1.2 / 1.0$ & $1.6 / 1.4 / 0.9$ & $1.8 / 2.4 / 1.5$ \\
Polymer & 2.4 & $1.1 / 1.1 / 0.9$ & $1.5 / 1.4 / 0.7$ & $2.1 / 2.9 / 1.6$ \\
Polymer & 3.4 & $1.1 / 1.1 / 0.9$ & $1.5 / 1.3 / 0.8$ & $2.1 / 3.4 / 1.7$ \\
Cement & 1.5 & $1.0 / 1.0 / 0.9$ & $1.0 / 1.5 / 1.2$ & $1.2 / 2.0 / 1.2$ \\
Cement & 3.5 & $1.0 / 1.2 / 0.9$ & $2.2 / 3.2 / 1.9$ & $3.3 / 3.0 / 2.5$ \\
Cement & 4.5 & $1.3 / 1.1 / 0.9$ & $2.2 / 4.1 / 2.0$ & $4.6 / 3.5 / 2.5$ \\
Cement & 6.0 & $1.4 / 1.2 / 1.0$ & $2.4 / 5.0 / 2.3$ & $6.1 / 5.8 / 3.7$ \\
Ref. & Rel. & $1.0 / 1.0 / 1.0$ & $1.0 / 1.0 / 1.0$ & $1.0 / 1.0 / 1.0$ \\
Ref. & Abs. ${ }^{*}$ & $179 / 165 / 196$ & $15 / 14 / 26$ & $4.9 / 4.4 / 7.5$ \\
\hline
\end{tabular}

${ }^{*} \mathrm{MPa}$ for $M_{R}$ tests, $\mathrm{kN}$ for $\mathrm{CBR}$ and compressive strength tests.

of material mineralogy and grading on the performance of treated and untreated granular materials.

On the opposite of what was anticipated, it can be pointed out that in general, for the three tests, the higher absolute results are not especially obtained for the grading that shows the higher dry density.

It can also be noticed that for every grading and mineralogy combination, the performance of granular material is better when treated with stabilization agents than when treated with dust suppressant.

When tested with natural brine or calcium chloride, the relative results for resilient modulus, bearing capacity and compressive strength are lower for the basalt and the limestone compare to the granitic gneiss. Also, the stabilization products (polymer emulsion and cement) improve the bearing capacity and compressive strength results for every mineralogy and grading. On the other hand, any product shows a significant improvement for the resilient modulus test except some particular combination of grading and mineralogy of granular materials treated with cement.

\section{Discussion}

It should be noticed that for the discussion, the emphasis is on the relative results for each mineralogy rather than the absolute results between the mineralogy to make sure that the result discussed remain realistic and practical. In fact, for economic matter, road network managers have to deal with the mineralogy on the road surface. It would be too much expensive to take off all the granular material in place and replace it by another type of aggregate. The idea here is to extract the best of the type of aggregate in place by treated it or by trying to modify his grading. So, for each mineralogy, it is interesting to find out the optimal grading for each product.

It is also important to notice that the discussion is based on the influence of grading and mineralogy on the performance of treated granular materials. Thus, for each additive, the concentration that fits with the relative results hold for the next figures are, for every products tested, the concentration that allows the best relative results. At least three concentrations have been tested for every product to make sure that the additives are used at an optimal concentration (Beaulieu et al. [10]).

On one hand, it can be noticed that in general, the mechanical performance decreases when the concentrations of dust suppressants increase. On the other hand, the mechanical performance increases when the concentrations of stabilization agents increase.

Tables 4 and 5 show that dust suppressant do not improve the mechanical characteristics of untreated basalt and limestone. In contrast, dust suppressants seem to be more appropriate for granitic gneiss.

Table 3 shows a little improvement of mechanical characteristics when granitic gneiss is treated with dust suppressants compared to untreated material. The none-tolittle improvement of granular materials treated with dust suppressants may be explained by the crystallization within the granular material voids which may increase the cohesion forces in the elastic range but seems to weaken the general strength of the granular skeleton at high deformations. The two dust suppressants tested may decrease the grain to grain frictional forces when materials are submitted to high shearing forces due to their water retention capacities. At the same time, this characteristic explains the capacity of those products to reduce dust. 

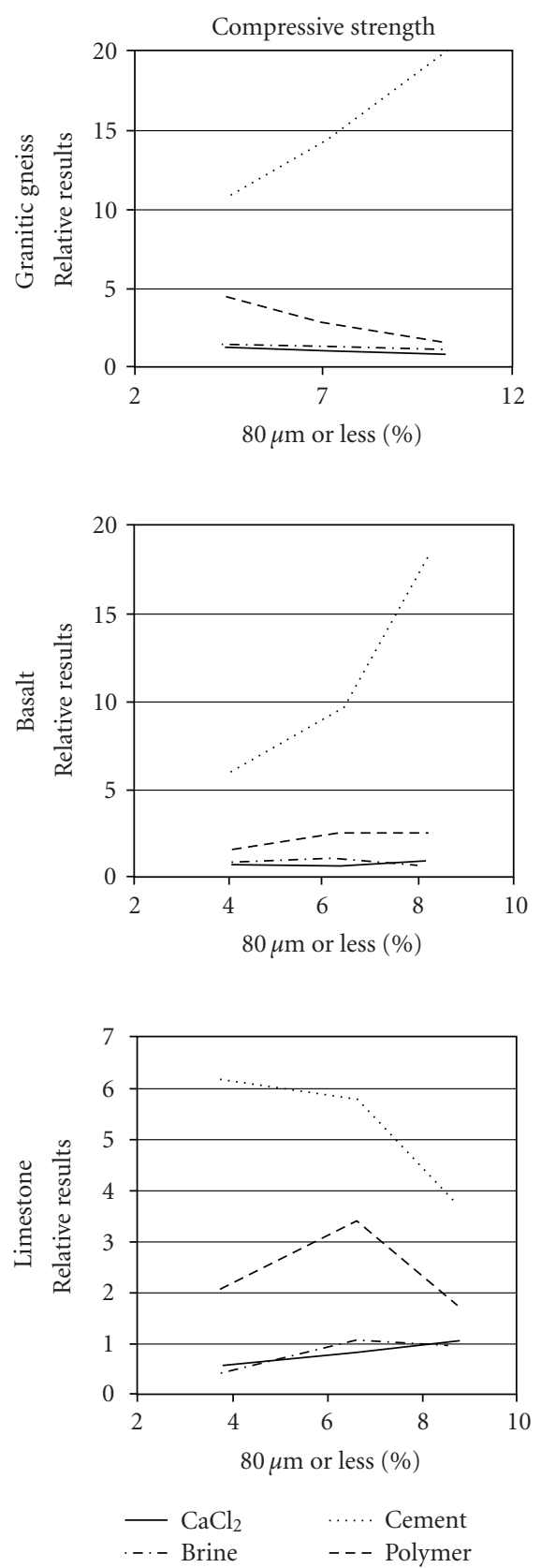

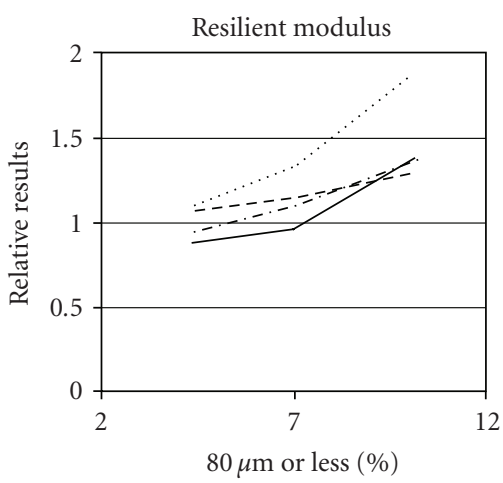

(a)

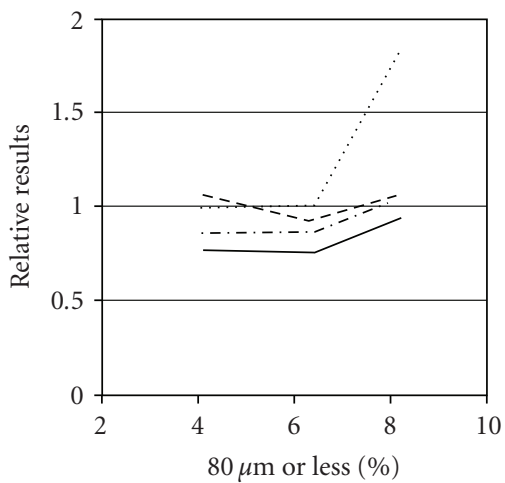

(b)

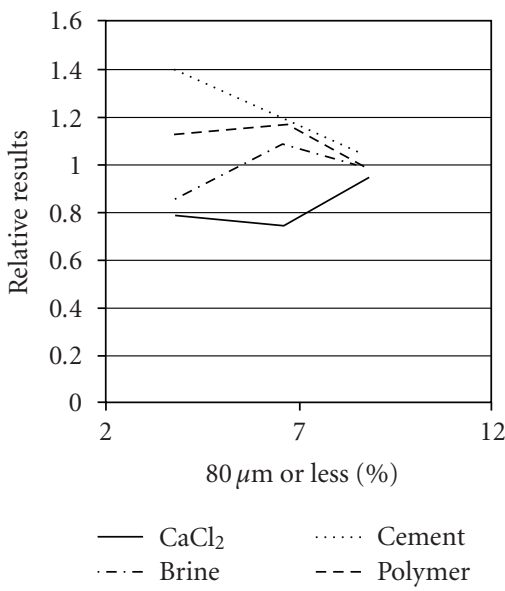

(c)
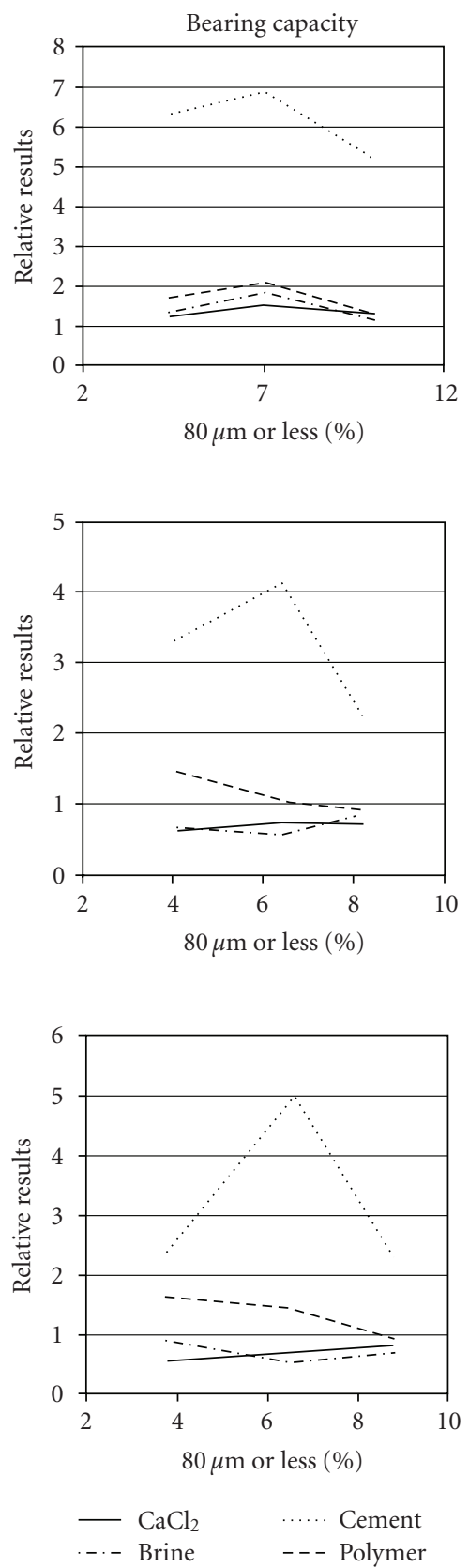

FIGURE 7: Relative results for every products and every grading for granitic gneiss (a), basalt (b) and limestone (c).

moreover, Tables 3, 4, and 5 show that usually the mechanical characteristics of every type of aggregate improve when it is treated with stabilization agents.

For a given mineralogy, Figure 7 shows that grading influences the performance of granular material. Again, for every product, the concentration that shows the best result has been hold for the figures.

In some cases, for the same product and the same mineralogy, changing the grading can double up some mechanical characteristics and thus improves the performance of the treated granular material compared to untreated material.
By referring to Table 1, it can be pointed out that for granitic gneiss, the higher is dry density, the better are the results for compressive strength test for all the products except for cement. This result can be explained by the fact that the cement matrix seems to be stronger with smaller grains which allow stronger cohesion forces. In fact, the cement reacts and fixes the smaller grains together and thus makes the granular material a lot more resistant to shear stresses.

Also, it should be noticed that for the granitic gneiss with the highest dry density, the coefficient of uniformity $\left(C_{u}\right)$ 

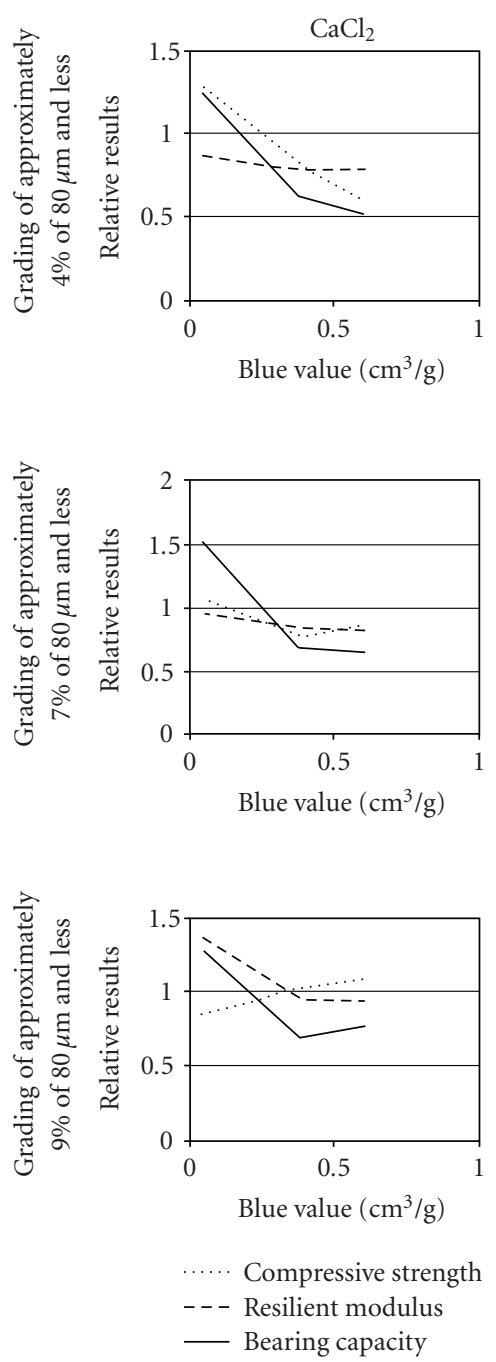

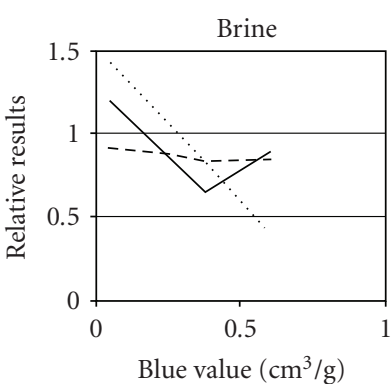

(a)

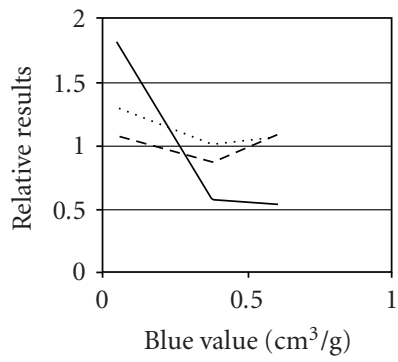

(b)

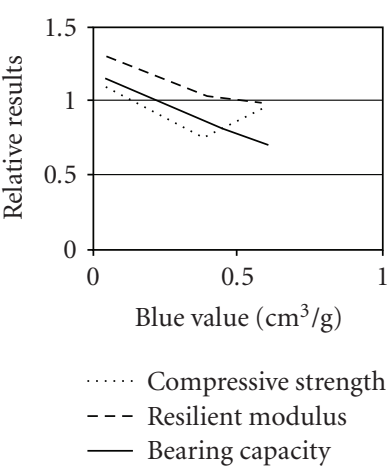

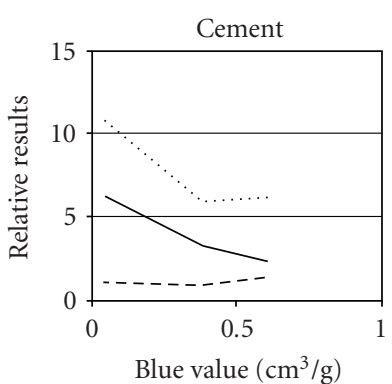
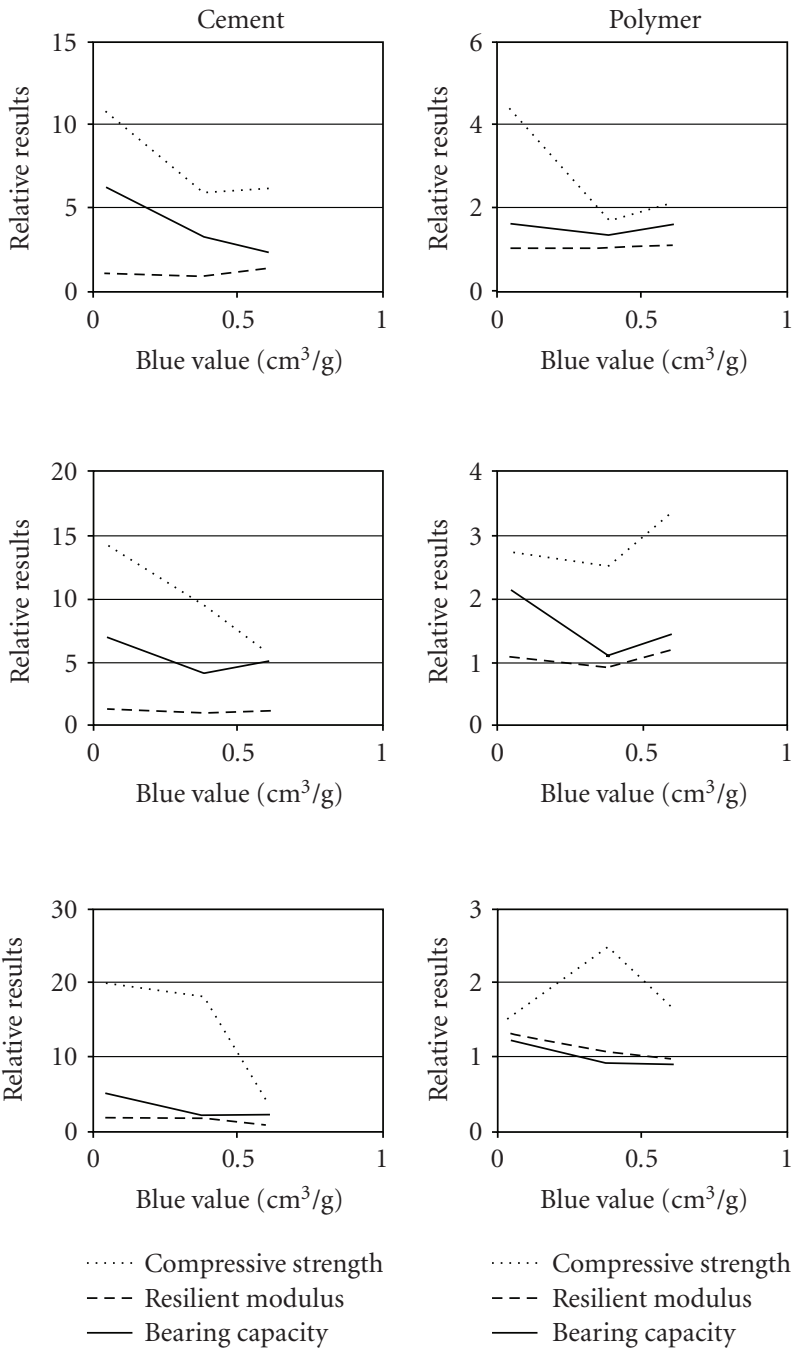

(c)

FIGURE 8: Relative results for every products and every specific surface area for a grading of approximately $4 \%$ of $80 \mu \mathrm{m}$ and less (a), $7 \%$ of $80 \mu \mathrm{m}$ and less (b) and $9 \%$ of $80 \mu \mathrm{m}$ and less (c).

is high. In fact, for a grading of $4,4 \%$ of $80 \mu \mathrm{m}$ grain-size and less, the $C_{u}$ has a value of 40 which means a large grain size distribution. This variability of the grain-size allows an arrangement of the granular material with a minimal void content. Thus, the mechanical characteristics of the aggregate are improved. It appears that for this grading, the space left by the arrangement of the larger grain-size is efficiently filled by the smaller grain-size which is translated by an optimal bearing capacity.

For treated granitic gneiss (no matter the product is), the relative results for every tests seem to be optimal for the grading $7 \%$ of $80 \mu \mathrm{m}$ grain-size or less.

So, on one hand, additives seem to be more efficient in presence of a critical value of $80 \mu \mathrm{m}$ grain-size or less. On the other hand, a percentage passing $80 \mu \mathrm{m}$ too high has the opposite effect and decreases the mechanical characteristics of the aggregate except for high concentrations of cement where cementitious links seem to be created. The influence of grading on basalt for treated granular material is very similar to granitic gneiss but the relative results are a little lower.

Besides, for limestone mineralogy treated with cement, the performance of granular material decreases when the smaller grain-size percentage increases even if the $C_{u}$ is maximum for high percentage passing $80 \mu \mathrm{m}$ grain-size. This result is probably due to the presence of clay in limestone. The cement does not react to create a cement matrix because clay already fills the space. Thus, cement appears to be more efficient with mineralogy without clay.

Basalt and limestone treated with dust suppressants are less efficient than untreated materials but in general do not seem to be affected by the grading and the grain-size percentage of $80 \mu \mathrm{m}$ and less.

Figure 8 shows that for approximately the same percentage of $80 \mu \mathrm{m}$ grain-size and less, the mineralogy influences the performance of granular material treated with stabilization agents or dust suppressants. 

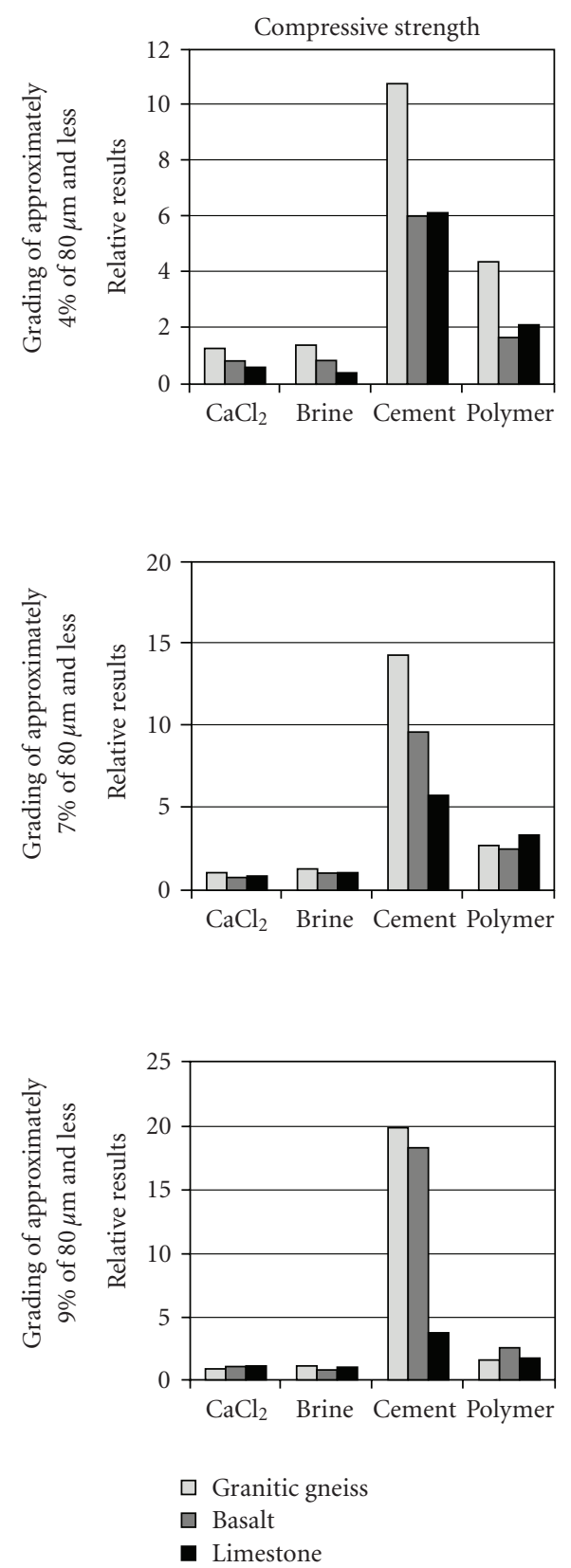
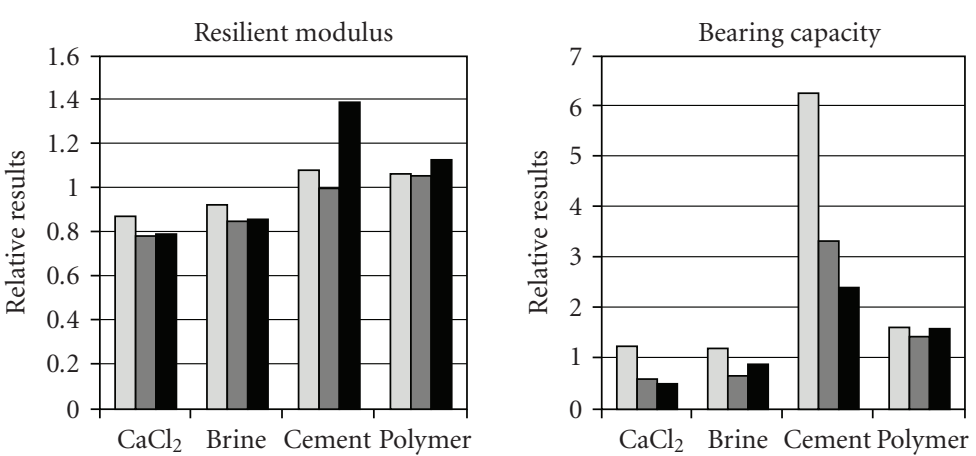

(a)

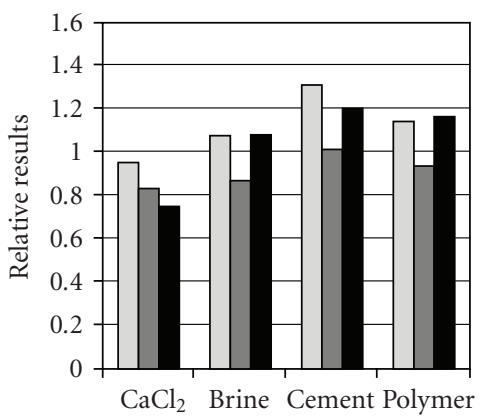

(b)
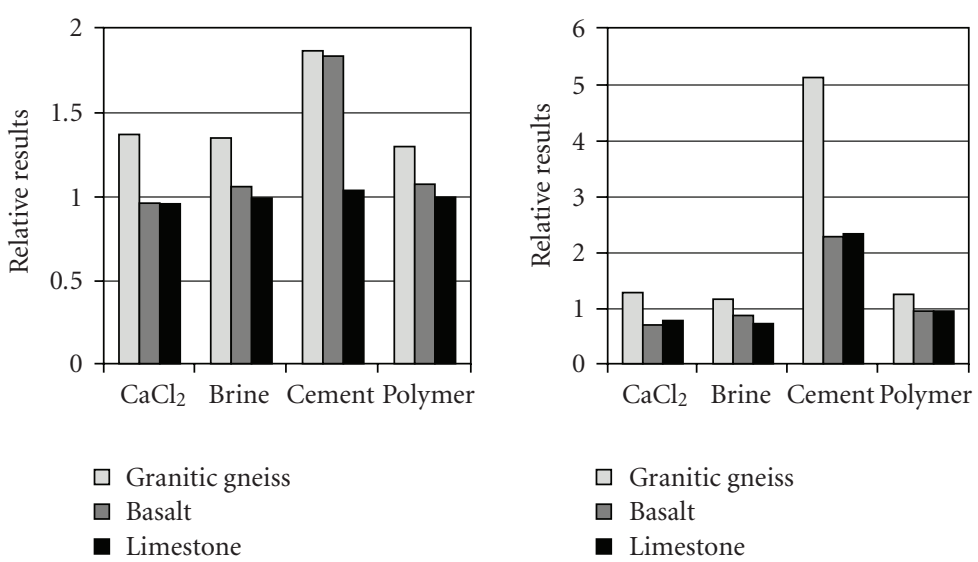

(c)

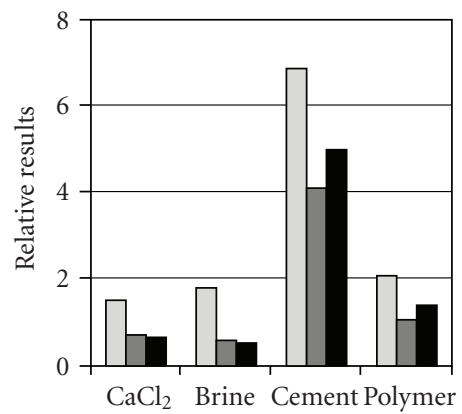

FIGURE 9: Relative results for every products and every mineralogy for a grading of approximately $4 \%$ of $80 \mu \mathrm{m}$ and less (a), $7 \%$ of $80 \mu \mathrm{m}$ and less (b), and $9 \%$ of $80 \mu \mathrm{m}$ and less (c).

For this figure, mineralogy is presented in terms of methylene blue values that were determined according to LC 21-255 (MTQ [11]). The higher is the blue value, the higher is the specific surface area of the granular material. Granitic gneiss, basalt, and limestone have, respectively, blue value of $0.046,0.383$, and $0.600 \mathrm{~cm}^{3} / \mathrm{g}$.

Limestone is the mineralogy that has the highest blue value. This result was anticipated. In fact, limestone usually contains clay which has very high specific surface area. Thus, the purpose of Figure 8 is to bring out if specific surface area influences the interaction between stabilization agents or dust suppressants and granular materials.

First, it can be pointed out that in general, granitic gneiss shows the highest increase of performance when it is treated with dust suppressants or stabilization agents.

Furthermore, limestone and basalt have approximately the same performance and show great mechanical improvement when treated with stabilization agents.

Again, for every product, the concentration that shows the bests results has been hold for the figures. The general 
trend is that for every product and every grading, the relative results decrease when the specific surface area increases.

In the opposite, for a grading of approximately $7 \%$ of $80 \mu \mathrm{m}$ and less, the performance of the polymer emulsion is greater with high specific surface area granular material.

The bearing capacity relative results are optimal for granitic gneiss and decrease quickly when the specific surface area increases. For high specific surface area values, relative results aim toward a steady state. In fact, it seems that when a critical value is obtained, the increase of specific surface area has less influence on the bearing capacity.

There is a little influence of specific surface area on the resilient modulus of treated granular materials for the grading of approximately $9 \%$ of $80 \mu \mathrm{m}$ grain-size and less. For this grading, relative results decrease when the specific surface area increases. For the two other gradings, no significant change is noticed.

As a general trend, it can be figured out that for every grading, the performance of granular materials treated with dust suppressants or stabilization agents decreases when the specific surface area increases.

In addition, Figure 9 shows that granitic gneiss bearing capacity relative results are slightly higher than 1 for the two dust suppressants. However, the bearing capacity relative results obtained for the basalt and the limestone are significantly lower than the ones previously obtained for the granitic gneiss.

Since the general trend shows that both bearing capacity and resilient modulus relative results are higher than 1 , the polymer emulsion is thus a better choice for maintaining or slightly improving the mechanical characteristics than the natural brine or the calcium chloride even though the performance gains are small (see Figure 9).

The addition of cement to the granitic gneiss tested in this study showed an increase of bearing capacity relative results up to $690 \%$. The effect of cement is approximately the same for the basalt and limestone with an increase of bearing capacity relative results up to $500 \%$. This is mainly because the cement particles are less dispersed within the basalt and the limestone granular skeleton in comparison to the granitic gneiss granular skeleton, mainly because of the gradation. In fact, basalt and limestone gradations (Figures 2 and 3) do not differ too much while granitic gneiss gradation contains more sand which can explain the facility of the cement particles to be dispersed.

For limestone treated with cement, the relative results for resilient modulus tests decrease when the percentage of $80 \mu \mathrm{m}$ grain-size and less increases. Again, this result can be explained by the fact that the cement does not react in order to create a cement matrix.

It can be pointed out that for a grading of approximately $9 \%$ of $80 \mu \mathrm{m}$ grain-size and less, there is no significant difference on the performance of granular materials treated with calcium chloride, brine, or polymer emulsion. In fact, the relative results on the performance of the granular materials treated with one of these three products are very similar, no matter the mineralogy is.
Thus, polymer emulsion does not seem to be appropriate for granular materials with high percentage of $80 \mu \mathrm{m}$ grainsize and less. It can be concluded that the cement mechanical stabilization, as measured in this study, is much higher than the polymer emulsion stabilization especially at high cement application rates.

Polymer emulsion seems to be more appropriate for limestone. Indeed, for the polymer emulsion, the difference of performance between limestone and granitic gneiss is less than the performance between limestone and granitic gneiss for the three other products. Thus, in presence of limestone, the polymer emulsion is certainly a choice to be considered. This result takes place maybe because of the macromolecules of the polymer emulsion that link the clay particles together which help improving the mechanical characteristics.

Finally, as a general trend, it can be concluded that none to little mechanical improvement is measured when dust suppressant is added to granitic gneiss, basalt, or limestone granular materials tested in this study.

\section{Conclusion}

The performance of unpaved aggregate roads can be affected by the quality of the granular materials used, the mineralogy of the granular material and the type of dust suppressants or stabilization agents used. This paper presented the results of a laboratory study aimed at measuring the effects of different mineralogy and grading combinations on the performance of treated and untreated granular materials measured with bearing capacity, resilient modulus, and compressive strength tests. Granitic gneiss, basalt, and limestone sources were compared. Treated (stabilized) and untreated results are presented. The performance of treated granular materials is presented in terms of relative results.

On average, for granular materials treated with one of the two dust suppressant, the bearing capacity, the resilient modulus, and the compressive strength relative results are higher for granitic gneiss followed by basalt and limestone, respectively. Overall similar treads are found for treated samples with stabilization agents. However, polymer emulsion seems to be a product more appropriate for limestone. The highest bearing capacities and compressive strengths (within a given mineralogy class) are found with the cement followed by the polymer emulsion, whereas both the brine and calcium chloride showed little to no gains. Increasing the product contents has no direct effect on increasing the mechanical performance of the treated granular materials. The performance depends on the mineralogy and the grading combination of the granular materials.

The results of this study will help to guide the authors for future full-scale in situ testing which will later be reported as part of this project.

\section{Acknowledgments}

The authors wish to thank NSERC and all the partners (FP Innovations, Holcim, Bitume Québec, Junex, Les Entreprises Bourget, Transport Québec, SDBJ, and Midwest Industrial 
Supply) involved in the CARRLo project for their financial support in this research project.

\section{References}

[1] T. G. Sanders, J. Q. Addo, A. Ariniello, and W. F. Heiden, "Relative effectiveness of road dust suppressants," Journal of Transportation Engineering, vol. 123, no. 6, pp. 393-397, 1997.

[2] G. Doré, P. Pierre, S. Juneau, and E. Stephani, "Établissement de données techniques pour la saumure naturelle Solnat utilisée comme abat-poussière sur les chaussées et analyse comparative avec le chlorure de calcium," Rapport GCT-200504, Département de Génie Civil, Université Laval, Quebec, Canada, 2005.

[3] L. Pelletier, Étude comparative de la performance en laboratoire de matériaux granulaires stabilisés utilisés comme surfaces de roulement pour les chaussées non revêtues, Mémoire de Maîtrise, Université Laval, Québec, Canada, 2007.

[4] P. Pierre, L. Pelletier, G. Légère, S. Juneau, and G Doré, "Comparative laboratory study of shear behaviour of granular materials stabilized with dust reducing products," in Proceedings of the CSCE Annual General Meeting \& Conference, Yellowknife, NT, Canada, 2007.

[5] P. Pierre, J.-P. Bilodeau, G. Légère, and G. Doré, "Laboratory study on the relative performance of treated granular materials used for unpaved roads," Canadian Journal of Civil Engineering, vol. 35, no. 6, pp. 624-634, 2008.

[6] G. Bergeron, "Retraitement en place à Transports Québec: Résultats des suivis de performance de 1991 à 2000," Service des Chaussées, Routes et Structures, Innovation Transport, pp. 15-25, 2000.

[7] N. Pouliot, "Traitement de surface sur routes gravelée, Direction du laboratoire des chaussées (DLC)," Bulletin d'Information Technique, vol. 9, no. 3, 2004, Ministère des Transports du Québec.

[8] R. L. Santoni, J. S. Tingle, and S. L. Webster, "Stabilization of Silty Sand with Nontraditional Additives," Transportation Research Record 1787, National Research Council, Washington, DC, USA, 2002, pp. 61-70.

[9] P. Pierre, "Amélioration de la qualité des chemins d'accès aux ressources et routes locales dans le contexte canadien, subvention de recherche et développement coopératrice," CRSNG, 2005.

[10] L. Beaulieu, P. Pierre, and S. Juneau, "Field test program of stabilization on a principal forest road," in Proceedings of the Road Dust Management Practices and Future Needs Conference, San Antonio, Tex, USA, 2008.

[11] Ministère des Transports du Québec, "GranulatsDétermination de la valeur au bleu de méthylène des sols et des granulats (LC 21-255)," in Procédure du Laboratoire des Chaussées, Ministère des Transports du Québec, Québec, Canada, 2001. 

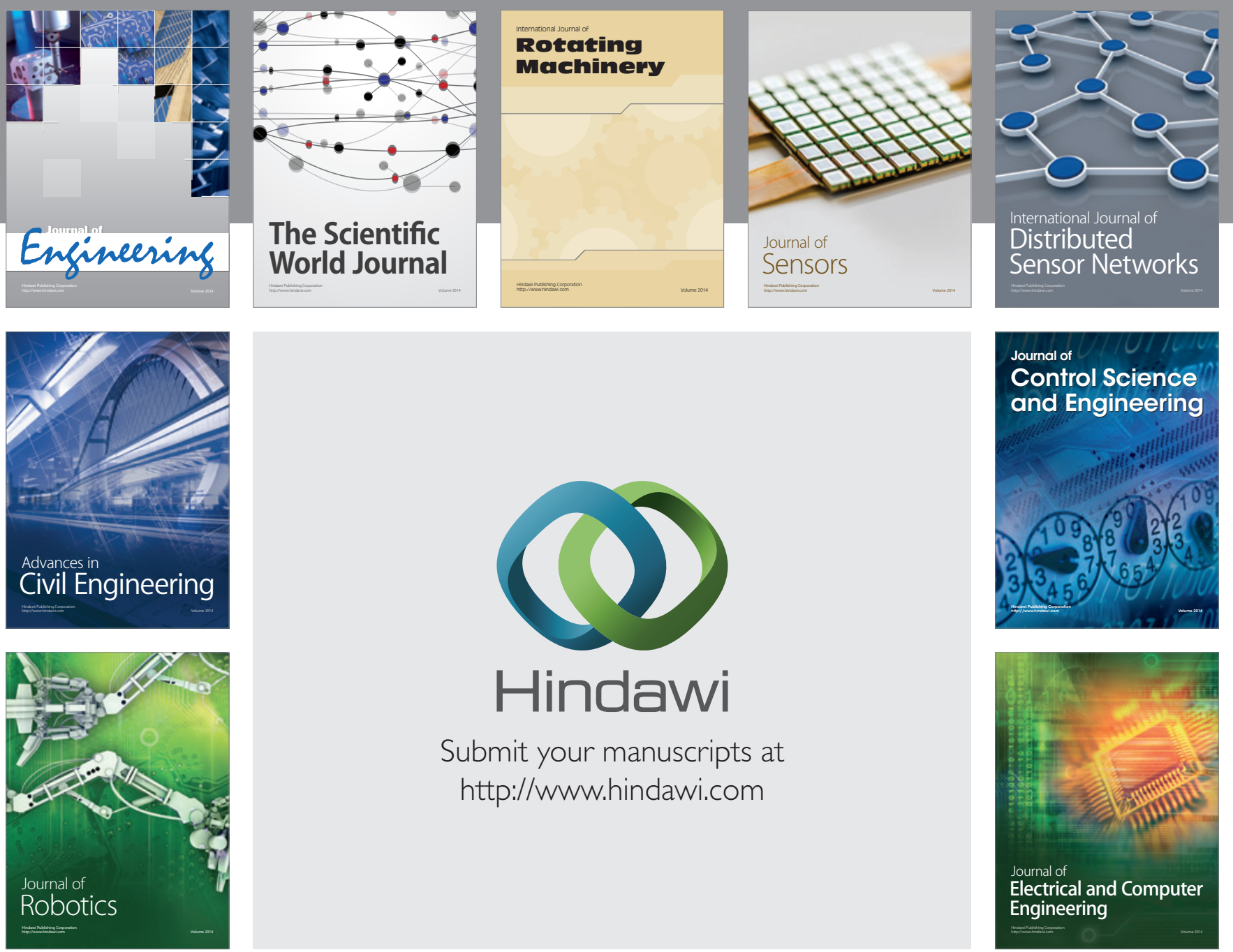

Submit your manuscripts at

http://www.hindawi.com
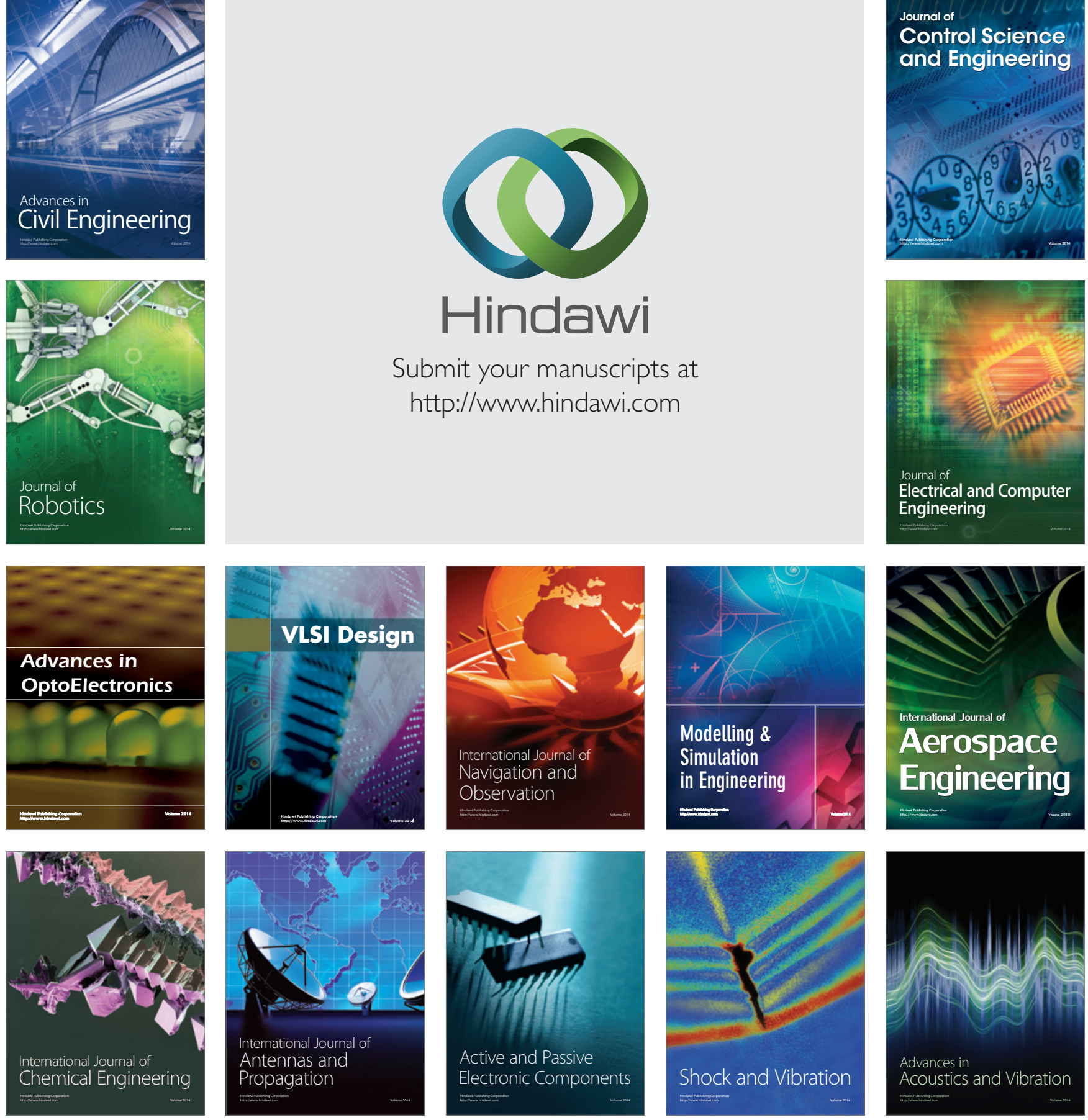